\title{
AS FICHAS DE CULTURA NO MÉTODO DE ALFABETIZAÇÃO DE PAULO FREIRE: IMAGEM, POLÍTICA E ESTÉTICA
}

DOI: $10.48075 / R I . V 24 I 2.26636$

Luciana Dilascio Neves ${ }^{1}$

Aristóteles Berino ${ }^{2}$

RESUMO: O texto reflete sobre a concepção estética-política do processo educativo de Paulo Freire a partir da utilização das fichas de cultura no Método de Alfabetização de Adultos. As fichas apresentavam-se como elemento de codificação, expressivas de situações existenciais que predispunham um estímulo elaborador e coparticipante não só no processo de alfabetização, mas também na movimentação criadora da própria maneira do pensar. Temos como pressuposto observar a utilização das fichas a partir de uma dinâmica no campo das imagens, que busca uma superação da dicotomia entre palavras e realidades - necessária superação expressa em Pedagogia do Oprimido - a partir da dimensão de um saber que é simultaneamente crítico e estético; como processo em contínua reelaboração, pelo qual a compreensão intelectiva se relaciona às experiências de vida, também sensível e intuitiva, daqueles sujeitos participantes dos Círculos de Cultura, como modo de manter o vínculo entre as experiências e a compreensão, entre as palavras e as realidades. Para pensar o uso e implicações destas fichas no processo educativo de Paulo Freire, utilizamos o próprio pensamento do educador, assim como alguns de seus interlocutores. Estabelecemos breve análise sobre as fichas de cultura, correlacionando também com autores no campo da imagem e da produção artística-cultural. Buscou-se refletir a relação das fichas de cultura enquanto pedagogia da imagem e procedimento que contribui para superação da dicotomia entre representação e realidade, e para dimensão criadora do pensar e do fazer.

Palavras-chave: Fichas de Cultura; Imagem; Criação.

\section{CULTURE CHARTS IN PAULO FREIRE'S LITERACY METHOD IMAGE, POLITICS AND AESTHETIC}

\footnotetext{
${ }^{1}$ Professora do Departamento de Artes da Universidade Federal Rural do Rio de Janeiro (UFRRJ). Doutoranda do Programa de Pós-Graduação em Educação, Contextos Contemporâneos e Demandas Populares (PPGEDUCUFRRJ). E-mail: Idneves2014@gmail.com

${ }^{2}$ Professor do Departamento de Educação e Sociedade da Universidade Federal Rural do Rio de Janeiro (UFRRJ) e do Programa de Pós-Graduação em Educação, Contextos Contemporâneos e Demandas Populares (PPGEDUCUFRRJ). E-mail: aristotelesberino@yahoo.com.br
} 
ABSTRACT: The text reflects on the aesthetic-political conception of the educational process of Paulo Freire based on the use of culture charts in the Adult Literacy Method. The charts were presented as a coding element, expressive of existential situations that predisposed an elaborating and coparticipant stimulus not only in the literacy process, but also in the creative movement of the particular way of thinking. We have as an assumption, the idea of thinking about the use of the charts based on a dynamic in the field of images, which seeks to overcome the dichotomy between words and realities - a necessary overcoming expressed in Pedagogy of the Oppressed - from the dimension of knowledge that is both critical and aesthetic ; as a process in continuous re-elaboration, by which the intellectual understanding is related to the subjects' life experiences, also sensitive and intuitive, of those subjects participating in the Culture Circles, as a way of maintaining the connection between experiences and comprehension, between words and realities. In order to think about the use and implications of these charts in Paulo Freire's educational process, we use the educator's own thoughts, as well as some of his interlocutors. We have established a brief analysis on the culture charts, also correlating with authors in the field of image and artistic-cultural production. We sought to reflect the relationship of the culture charts as an image and procedure pedagogy that contributes to the overcoming of the dichotomy between representation and reality, and to the creative dimension of thinking and doing.

Key Words: Culture charts; Image; Creation.

"Não é devido à deterioração a que se submete a palavra amor no mundo capitalista que a revolução vá deixar de ser amorosa [...]" (Paulo Freire, Pedagogia do Oprimido, 2019, p. 110)

INTRODUÇÃO

Este texto procura estabelecer uma reflexão sobre a utilização das fichas de cultura no Método de Alfabetização de Adultos desenvolvido por Paulo Freire, visando demonstrar como esta utilização estabelece-se em correspondência com uma concepção de educação pensada em diálogo com uma prática de criação estética. Conforme Berino (2017a, p. 183), esta relação se explicita no dizer do educador ao afirmar que "El Educador es un político y un artista".

Embora a relação entre política e educação no pensamento de Paulo Freire seja mais reconhecida e afirmada, como aborda Aristóteles Berino (ibid.), a relação entre estética e educação está presente em várias passagens de sua obra, sendo ambas as dimensões, a política e a artística, "pertencentes a uma natureza comum de sua leitura de mundo", assim como de sua concepção educativa. Berino (2017b, s/p) enfatiza ainda a necessidade atual "de recuperar a unidade da relação entre o político e o estético na sua obra" como "uma via 
importante para manter vivo o seu pensamento", a despeito dos equívocos e destratos que distintas interpretações têm se pautado.

A vinculação entre estética e educação que pode ser encontrada em passagens da obra de Paulo Freire relaciona-se à experiência de criação, em oposição a tudo que já está pronto e concluído; experiência em que o processo é mais significativo do que os fins como resultado, e que o conhecimento é compreendido como "um ato político", e "por isso mesmo, como um ato criador" (FREIRE, 2011, p. 28).

Não temos a intenção de analisar o Método de Alfabetização de Adultos, mas sim, iremos pensar a utilização das fichas de cultura inseridas no processo do Método de Alfabetização, buscando refletir a coerência do uso das fichas dentro do sistema proposto, e as imbricações no seu pensamento estético-educativo.

\section{FICHAS DE CULTURA: IMAGEM E MONTAGEM DE SENTIDO}

Conforme Freire (2019b, p. 167), as fichas de cultura visavam "representações de aspectos da realidade", evocando "momentos do contexto concreto". Tendo sido elaboradas, em geral, como um desenho ${ }^{3}$, as fichas apresentavam uma "situação existencial" que possibilitava a percepção do tema e, por conseguinte, a expressão oral a ele referente (FREIRE, 1994). Logo, considerando toda uma investigação ${ }^{4}$ prévia que também era requerida, o método tinha como pontos iniciais o uso de uma imagem (uma ficha), que, segundo Berino (2017b, s/p), ainda que o momento mais lembrado, fosse o que ocorria a partir das "palavras geradoras" e das "famílias fonêmicas" - que uma vez combinadas dariam impulso à formação de novas palavras - , o uso da imagem referia-se a "um momento significativo da sua prática", e não um mero apêndice, dando sequência à discussão e ao diálogo a partir também do uso destas fichas de cultura.

\footnotetext{
${ }^{3}$ Conforme Berino (2017b, s/p), em Pedagogia do Oprimido (1970), e em Pedagogia da Esperança (1992), Paulo Freire relata também o uso de fotografia entre educadores norte-americanos.

${ }^{4}$ Paulo Freire (2019a, p. 140) menciona que a investigação da temática que dará base à prática "envolve a investigação do próprio pensar do povo". Investigação esta que ocorre antes e durante todo o processo desenvolvido, "seja pela conversação informal com os habitantes da área [...]", em que "irão registrando [...] a maneira de conversar [...] sua linguagem, suas palavras, sua sintaxe [...] a forma de construir seu pensamento" (p. 145-146). Cita, como genial exemplo de investigação, o escritor Guimarães Rosa, que segundo ensaio de Paulo de Tarso, "foi descobridor dos temas fundamentais do homem do sertão brasileiro" (p. 146).
} 
Encontramos correspondência entre este tipo de estruturação do Método, na sua concepção de que "a leitura do mundo precede a leitura da palavra, daí que a posterior leitura desta não possa prescindir da continuidade da leitura daquele. Linguagem e realidade se prendem dinamicamente" (FREIRE, 2011, p. 19-20). O que nos faz sinalizar, que o uso das fichas antecedendo o diálogo oral verbalizado, ou mesmo ocorrendo em paralelo a este diálogo, na ordenação do processo desenvolvido ${ }^{5}$, demonstra uma necessidade de requisitar antes uma experiência sensível e intuitiva dos sujeitos participantes, perante a vivência da realidade suscitada pela imagem.

Nem sempre pensamos o termo imagem de maneira restritiva à visualidade, ainda que, com relação às fichas de cultura, nos refiramos às imagens visuais. Contudo, entendemos a imagem como uma formação a partir de nossa estrutura receptiva, integrada por dados objetivos e subjetivos, ocorrida a partir de estímulos e acontecimentos diferenciados. Neste sentido, a poesia e a música, entre outras produções, também geram uma imagem; a imagem poética ou musical, por exemplo, de maneira que a utilização do termo não é pensada como uma equivalência direta da visualidade.

Conforme o poeta Otávio Paz (2003, p 50), a imagem poética tem sua maneira particular de recepção, produzindo uma narratividade diferente de uma outra mais discursiva. Para o poeta, "a maneira própria da comunicação da imagem, não é a transmissão conceitual. A imagem não explica: convida-nos a recriá-la, e literalmente, a revivê-la". É no âmbito desta particularidade receptiva da imagem que pensamos a utilização das fichas de cultura. Ainda que Freire (1994) não utilizasse o termo imagem, pensava as fichas como um elemento de codificação, expressivas de uma situação existencial, coparticipando e imprimindo um estímulo elaborador ao processo de alfabetização da linguagem, conciliando a esta uma repercussão e uma movimentação criadora na própria maneira do pensar. Pertence ao educando, "a sua criatividade e a sua responsabilidade na construção de sua linguagem escrita e na leitura desta linguagem (FREIRE, 2011, p. 29).

A perspectiva de pensar o uso das fichas de cultura como um momento do processo de alfabetização ligado a uma dinâmica no campo das imagens tem uma correlação com a visão crítica de Paulo Freire (2019a) que se encontra explicitada em Pedagogia do Oprimido, e na qual denuncia a dicotomia entre o discurso e a realidade. Para o educador, a palavra

\footnotetext{
${ }^{5}$ Em Cartas a Guiné Bissau (2019b, p. 173), Paulo Freire menciona que a ordem deste processo poderia variar de acordo com as especificidades das localidades.
} 
inautêntica gera formas inautênticas de pensar e existir: "Falar [...] em democracia e silenciar o povo é uma farsa. Falar em humanismo e negar os homens é uma mentira" (FREIRE, 2019a, p. 113), fruto desta dicotomia entre o que as palavras dizem e o que a realidade mostra, consequência da deterioração a que se submete as palavras no mundo capitalista (p. 110). A dicotomia gera a "palavra vazia", feita para iludir, para a manutenção de um status quo. A constante desarticulação entre narrativas e realidades fortalece a dominação, não sendo sem razão que instituições midiáticas e hegemonias políticas omitindo-se da responsabilidade sobre os conflitos de uma sociedade de classes pensada para o domínio e exploração, revestem-se de narrativas sobre justiça, fraternidade, amor, liberdade, entre outros termos conceituais desvinculados de sua práxis social.

É na compreensão deste contexto em que as palavras podem aparecer completamente esvaziadas de sentido, que Paulo Freire (2019a, p. 50-51) abraça esta dimensão do saber que não pode ser apenas racional, e pela qual objetividade e subjetividade aparecem "em permanente dialeticidade". Intelectivo e crítico sim, mas também estético, como processo em contínua construção e reelaboração, para que o pensamento não se deixe cristalizar em formas fixas e meramente abstratas. Para que sentidos e significados não estejam definidos a priori, mas se constituam em cada contexto e a cada processo: “Este é um pensar que percebe a realidade como processo, que a capta em constante devenir e não como algo estático" (FREIRE, 2019a, p. 47). A compreensão intelectiva e crítica precisa estar relacionada a toda experiência de vida do sujeito, relativa também a sua vivência sensível e intuitiva, como modo de manter o vínculo entre a experiência e a compreensão, entre as realidades e as palavras.

Para Freire (2019a, p. 121-122), o próprio "pensamento-linguagem" referido aos sujeitos em sua realidade precisava ser considerado na investigação dos temas e instauração do processo educativo, pois revela a percepção e a visão de mundo que os mesmos têm desta realidade. Linguagem e pensamento também se constituem dinamicamente; separá-los já é uma operação de mutilação dos sentidos em ambos. Por isso, é preciso reconhecer "as condições estruturais em que o pensar e a linguagem do povo, dialeticamente, se constituem" (FREIRE, 2019a, p. 121).

Ainda em Pedagogia do Oprimido, Freire (2019a, p. 136) aborda que o "tema gerador" que irá desencadear o processo de ensino e aprendizagem dialeticamente entre mediadores e alfabetizandos, deverá ser trazido do próprio "pensar dos homens referido à 
realidade", com seu modo de ser e de atuar sobre esta realidade, de maneira que o tema gerador possa instaurar um diálogo a partir de "dimensões significativas de sua realidade" (p. 134) e de sua existência. Argumenta, contudo, que a consciência dominada e dicotômica "fica na apreensão de suas manifestações periféricas" (p. 133), no que diz respeito à realidade percebida, captando-a por fragmentos isolados ou aspectos acidentais e secundários, sem perceber uma possível interação entre suas partes constituintes. Freire nos indica aí sua concepção do uso da imagem ${ }^{6}$ através das fichas:

Realmente, em face de uma situação existencial codificada ${ }^{7}$ (situação desenhada ou fotografada que remete, por abstração, ao concreto da realidade existencial), a tendência dos indivíduos é realizar uma espécie de "cisão" na situação que se lhes apresenta. Esta "cisão", na prática da descodificação, corresponde à etapa que chamamos de "descrição da situação". A cisão da situação figurada possibilita descobrir a interação entre as partes do todo cindido (FREIRE, 2019a, p. 135, [grifo nosso]).

Uma primeira tendência observada nos indivíduos, segundo Freire, seria de uma "cisão" na "leitura" de uma ficha de cultura. Uma necessidade de descrição de cada elemento ou representação isolada, no intuito de uma primeira compreensão, mais imediata. Didaticamente, é esta primeira fragmentação que possibilita um aprofundamento na imagem, a partir do diálogo, com a busca pela descoberta de significados advindos da interação entre suas partes. Procura assim, ao estimular uma descoberta a partir da interação entre as partes, propor uma movimentação nos sentidos, uma construção semântica a partir de dados objetivos e subjetivos suscitados nas experiências daqueles participantes, de maneira que o fluxo do pensar seja reconstituído ou reelaborado através do movimento que associa, relaciona e se desloca entre as partes ou representações isoladas. Para Freire (2019a, p. 135, [grifo nosso]), este todo que compõe as fichas, "passa a ganhar significação [na apreensão do participante] na medida em que sofre a 'cisão' e em que o pensar volta a ele, a partir das dimensões resultantes da cisão", e das interações constituintes da totalidade.

Ao invés da imposição de um discurso pronto, a força da estratégia é permitir e estimular que a montagem do sentido seja feita pelos participantes. E é quando estes

\footnotetext{
${ }^{6}$ Também nesta passagem de Pedagogia do Oprimido, ressaltamos que Paulo Freire não usa o termo imagem, sendo este uso, uma proposição aqui estabelecida para pensar as fichas de cultura.

7 No tocante à metodologia para as fichas de cultura, Paulo Freire se utiliza dos termos codificação e descodificação: “A codificação de uma situação existencial é a representação desta, com alguns de seus elementos constitutivos em interação. A descodificação é a análise crítica da situação codificada $(2019$, p. 135). 
participantes começam a fazer a montagem do sentido por eles mesmos, que as representações deixam de ser abstratas e vazias de sentido para se vincularem à experiência.

\section{DIALÉTICA E CORRELAÇÕES}

De acordo com Benjamin (1994a, p. 88), “o programa pedagógico do marxismo é determinado pela dialética do ato de ensinar e o de aprender". Toda prática de Freire (2019a) alinha-se com um programa dialético neste âmbito. Abrimos um parêntese aqui para estabelecermos uma correspondência entre a prática do educador e alguns exemplos de produções a partir de princípios dialéticos relacionados à noção de montagem. No primeiro exemplo, buscamos no teatro épico ${ }^{8}$ de Bertolt Brecht (1898-1956):

O teatro épico [...] não se propõe a desenvolver ações. Mas representar condições. Ele atinge essas condições [...] na medida em que interrompe a ação. [...] Refiro-me ao procedimento da montagem: pois o material montado interrompe o contexto no qual é montado. [...] A interrupção da ação [...] combate sistematicamente qualquer ilusão por parte do público. Essa ilusão é inutilizável para um teatro que se propõe tratar os elementos da realidade no sentido de um ordenamento experimental [...] portanto, não reproduz as condições, ele as descobre. A descoberta das condições se efetua por meio da interrupção das sequências. Mas a interrupção não se destina a provocar uma excitação, e sim, a exercer uma função organizadora. Ele imobiliza os acontecimentos e com isso obriga o espectador a tomar uma posição quanto à ação [...] (BENJAMIN, 1994b, p. 133)

No processo da montagem do teatro de Brecht, o material montado "interrompe o contexto no qual é montado" e, é nesta interrupção que visa romper com a transmissão direta de uma mensagem ao público a partir de uma estruturação naturalista ou ilusionista, combatidas por ele. Ao contrário, a partir de fragmentos de situações ou representações retiradas do real social, paralisa a ação e chama o público a participar do processo montado, no intuito de indagar sobre seu próprio posicionamento diante da situação exposta.

O segundo exemplo, retiramos dos processos de montagem fílmica do cineasta russo Serguei Eisenstein (1898-1948). Sem nos aprofundarmos nos processos aqui exemplificados, a montagem dialética em Eisenstein (2002), muito correspondente à prática marxista em que

\footnotetext{
${ }^{8}$ Conceito de teatro desenvolvido por Brecht, opondo-se ao teatro clássico, narrativo e naturalista, tendo como característica combater "sistematicamente qualquer ilusão por parte do público" (BENJAMIN, 1994, p 133), buscando fazer revelar as condições sociais pelo método do distanciamento e da montagem.
} 
"para compreender o mundo, é preciso compreender seus antagonismos" (AMIEL, 2010, p. 54), se efetiva pela justaposição de dois ou mais termos, situações ou representações retiradas da realidade, cultural, social e/ou histórica. Em Eisenstein (2002), estes termos são, em geral, pensados por antagonismos e conflitos, construídos pelas imagens e planos em oposição - e que possibilita fazer repercutir, nos espectadores, as relações e implicações que se desencadeiam a partir dos termos justapostos. Pode-se dizer que há uma função didática no cinema deste cineasta que diz respeito a expor e explicitar o conflito e as contradições, no propósito da revolução e da tomada de posição das massas. Através de seus escritos, observamos a importância que o cineasta atribuía à imagem. Considerava que, no contexto da revolução, a imagem era muita mais apropriada do que o discurso verbal, justamente porque, no choque entre referências, pensamentos e sentimentos, abre maior espaço para a experiência do espectador, requisitando "uma dimensão a elucidar" (AMIEL, 2010, p. 56). Enquanto o discurso verbal, muitas vezes, pode tender mais para a explicação ou conclusão, esta dimensão a elucidar da imagem garante a participação do observador, pois tal revelação precisa ser criada e recriada, e em suma, "montada" na experiência do mesmo.

Estando a prática de Paulo Freire vinculada a um princípio dialético, e considerando as diferenças existentes, buscamos estabelecer algumas correlações com os exemplos mencionados, em especial quanto à procura por fazer dos participantes sujeitos ativos no processo.

A questão que se impunha para o educador era o tipo de dinâmica sobre as imagens que eram utilizadas. Era esta dinâmica que ele intencionava fazer corresponder a um processo de criação, no intuito de elaboração e reelaboração dos sentidos e dos significados, advindas dos sujeitos participantes dos Círculos de Cultura, em todas as etapas do processo, "exteriorizando sua visão de mundo, sua forma de pensá-lo" (FREIRE, 2019a, p. 136). Buscava estimular naqueles participantes a possibilidade de dizer o mundo e de construí-lo permanentemente. Para Freire (2019a, p. 50-51), "não se pode pensar em objetividade sem subjetividade. Não há uma sem a outra, que não podem ser dicotomizadas". A utilização educativa das fichas de cultura é uma dinâmica no âmbito das imagens, como modo de conhecimento, tendo por base um processo que procura mais as descobertas do que a compreensão como um resultado único e determinado. 


\section{O POLÍTICO E O ESTÉTICO NO MÉTODO PAULO FREIRE}

De acordo com Fávero (2012, p. 1), no início dos anos sessenta, são "criados os movimentos e centros de cultura popular no país - à qual se subordinava a educação popular". Segundo ele, o aparecimento de vários movimentos de cultura popular, não só no Brasil, mas no mundo, se justifica numa polarização; oposição entre cultura popular e uma cultura dominante instituída que embora se declare destinada a todos, é aparelho de regulação da cultura e da educação em prol de seus próprios interesses de classe. No Brasil, os vários movimentos surgidos "assumem à crítica à dominação cultural dos centros hegemônicos" (FÁVERO, 2012, p. 6) e "só na esfera política encontram seu sentido último" (p. 5), com uma empreitada clara e sem dissimulação "à formação da consciência política ativa das massas" (p. 3).

Conforme Schwarz (2008, p. 80), o Movimento de Cultura Popular (MCP), em Pernambuco, começou em 1959, quando Miguel Arraes, sendo prefeito, se candidatava a governador, tendo assim uma finalidade eleitoral para alfabetizar as massas, já que, naquele período, o analfabeto não votava. No entanto, como menciona, as ações culturais do MCP tinham amplitude e deu impulso a iniciativas, tal como o Método Paulo Freire de Alfabetização, que não concebia "a leitura como técnica indiferente":

\footnotetext{
Os professores [...] iam às comunidades rurais, e a partir da experiência viva dos moradores alinhavam assuntos e palavras-chaves - "palavrasgeradoras", na terminologia de Paulo Freire - que serviriam simultaneamente para discussão e alfabetização. Em lugar de aprender humilhado, aos trinta anos de idade [...] o trabalhador rural entrava, de um mesmo passo, no mundo das letras e no dos sindicatos, da constituição, da reforma agrária, em suma, dos seus interesses históricos (SCHWARZ, 2008, p. 80)
}

Como observa Berino (2019, s/p), uma das características do Método é que "criava as condições necessárias à própria aprendizagem através do interesse"; fator que alarmou às elites com relação ao alcance que o Método poderia ter. Através do Serviço de Extensão da Universidade de Recife e do MCP, Paulo Freire atuou nas campanhas de alfabetização, sendo a primeira e mais reconhecida a que ocorreu em Angicos, no Rio Grande do Norte. Em 1963, Freire foi convidado pelo presidente João Goulart para liderar uma campanha nacional de alfabetização, que tinha não apenas a perspectiva de conscientização das classes populares, 
como uma direta influência política no comportamento eleitoral; iniciativa interrompida com o Golpe Militar de 1964.

É possível perceber que antes do Golpe Militar, havia um processo no intuito de uma educação coletiva acontecendo, voltada para os interesses das classes populares; uma "educação coletiva em processo de acumulação crítica e formativa, que aproximava de modo inédito as classes sociais" (BUENO, 2008, p. 264), com Centros Populares de Cultura improvisando "teatro político em portas de fábricas, sindicatos, grêmios estudantis, e na favela, começava a fazer cinema e lançar discos" (SCHWARZ, 2008, p. 81).

Em meio a diversificados movimentos e ações de natureza popular que estiveram em cena no início dos anos sessenta, como menciona Fávero (2012, p. 9), "a proposta de educação de adultos de Paulo Freire foi elaborada no bojo deste "caldo ideológico'". No entanto, em meio às distintas concepções é necessário não unificar manifestações e ações, uma vez que inseridas num mesmo desejo de transformação da ordem vigente em um dado período, existem propostas múltiplas, e mesmo divergentes, consumadas por erros e acertos. Algumas destas manifestações também foram criticadas sob o argumento de agirem tal como o que criticavam e diziam querer transformar. Fávero $(2012$, p. 6) menciona que Marilena Chauí faz uma crítica radical à determinada posição do Manifesto do Centro de Cultura Popular (CPC), que, em sua visão, optava "por ser a vanguarda do povo, condutores", e a alguns conteúdos dos Cadernos do Povo Brasileiro, em que via "antes persuasão que discussão e esclarecimento". Não é nossa intenção aqui avaliar a pertinência desta crítica, mas considerar a importância de se atentar continuamente para uma coerência entre discurso e prática, principalmente no presente momento em que as acusações de doutrinação têm sido direcionadas genericamente aos movimentos de esquerda, a exemplo das que têm sido expressivamente dirigidas a Paulo Freire.

Em sua obra, O Nacional e o Popular na Cultura Brasileira, Chauí (1983) problematiza algumas questões a respeito de discursos e "representações" relativas aos temas Nacional e Popular. Representações tais como "povo" ou "nação" são apresentadas como imagens unificadoras, cujas extremas contradições e divisões que lhe são intrínsecas, aparecem estrategicamente ocultadas pela sociedade capitalista. Neste âmbito, a unidade de termos tais como Povo, Nação, Estado, ou ideias como liberdade e igualdade, se tornam representações abstratas e "irrelevantes na medida que as construções teóricas podem lhe conferir sentidos diversos e mesmo diferentes" (CHAUÍ, 1983, p.22), segundo finalidades 
particulares. Conforme Chauí (p. 35), “Marx assinala que a grande novidade introduzida pelo modo de produção capitalista [...] é a separação clara entre a relação social de exploração e de opressão e a relação impessoal de dominação", de modo que, "a forma do Estado capitalista lhe permite aparecer como dominação de ninguém e por isso ser representado como soberania nacional e popular".

Para Chauí (1983, p. 41), "a proliferação dos discursos sobre a nação" ou sobre o povo, sejam eles de esquerda ou direita, e que se pautam em dizer o que é o povo a partir destas representações abstratas, sem a construção de um processo em que se definam os próprios termos, e sem uma práxis efetiva e coerente, só fazem aumentar, a nosso ver, aquela distância entre as palavras e a realidade, anunciada por Paulo Freire.

A abordagem crítica que Marilena Chauí dirige a algumas manifestações imbuídas de proposta revolucionária refere-se, especialmente, ao distanciamento do processo dialético e ao problema de tender à doutrinação; situações em que não se instaura um processo porque o resultado se determina previamente, acabando por utilizar as mesmas estratégias de persuasão e manipulação dos centros hegemônicos. Um trecho da crítica feita ao aspecto doutrinário do Manifesto do CPC, pareceu-nos relevante de reflexão:

Ao terminar a leitura do Manifesto, uma pergunta sobe à garganta, quase
irreprimível: "O que é isto, companheiro?", tal a carga de deveres,
obrigações, vigilância e ascetismo que impregna a missão do "artista popular
revolucionário". [...] É preciso, no entanto, indagar de quem parte a
imposição de limites. [...] Depois de se vigiar e de se punir, depois de
tamanho moralismo e disciplina, como haveria de ser o "reino da liberdade"
para onde esse arauto conduziria o povo? (CHAUÍ, 1983, p. 89)

A pergunta que Chauí deixa em suspenso parece-nos oportuna para fazer refletir sobre a necessária coerência entre práxis e teoria. É neste sentido também que afirmamos a prática educativa de Paulo Freire como fundamentada no processo e fora de um sistema doutrinário. Para Berino (2019, s/p), não é um problema de doutrinação, como afirma seus detratores, mas de "politicidade". Ainda que, como mencionou anteriormente Schwarz (2008), o trabalhador entrasse simultaneamente no mundo das letras e da política, através de assuntos de seu interesse, havia a preocupação de não impor um conhecimento prévio ou buscar persuadir; mas criar um processo que permitiria àqueles sujeitos se posicionarem diante dos fatos e situações apresentadas, elaborando e reelaborando seu modo de conceber e pensar. 
É desta forma que o estético não deixa o político se estagnar em uma prática ortodoxa e modeladora, sendo coparticipantes da prática educativa.

\section{A PRODUÇÃO DAS FICHAS NA DINÂMICA DOS CÍRCULOS DE CULTURA}

Conforme Fávero (2012), encontramos distintas séries de desenhos elaborados para comporem as fichas de cultura, e que se relacionam com as situações e localidades em que o Programa foi realizado. A primeira das séries foi feita para a experiência de Angicos. Em geral, sendo encomendadas a um artista local. Segundo Fávero (2012, p. 10), os desenhos eram bastante simples, mas foram sendo enriquecidos durante as discussões nos Círculos de Cultura e as revisões a cada experiência que iam se sucedendo.

A segunda série de acordo com Fávero (2012, p. 10) teria sido confeccionada pelo Ministério da Educação (MEC) "e editada pelo Instituto Nacional de Cinema Educativo (INCE), em 1963, para a experiência de Brasília". E a terceira ${ }^{9}$, foi produzida pelo ceramista e pintor pernambucano Francisco Brennand (1927- 2019), elaborada para o Programa Nacional de Alfabetização, cuja experiência inicial ocorreu no início de 1964, no Estado do Rio de Janeiro, em áreas da Baixada Fluminense, sendo interrompida com o Golpe. Conforme Fávero (p. 11), a produção das fichas da terceira série por Brennand aconteceu por intermédio de Ariano Suassuna, que era um amigo em comum. Dentro do pouco espaço de tempo em que a prática educativa concebida e liderada por Paulo Freire ocorreu no Brasil, estes acontecimentos significam um trajeto de constantes buscas e diálogos, que marcam as reformulações nas características das fichas, e um processo de elaboração e reelaboração durante o próprio desenvolvimento da prática.

Nos Círculos de Cultura do Programa Nacional de Alfabetização, os desenhos eram reproduzidos em "diapositivos" (FAVERO, 2012, p. 11), sendo projetadas as fichas, numa espécie de "filminho".

A primeira ficha nas três séries mencionadas ${ }^{10}$, respectivamente Angicos, Brasília e Rio de Janeiro, têm como situação existencial, a relação do homem no mundo, com a natureza

\footnotetext{
${ }^{9}$ Fávero (2012, p. 10) menciona ainda uma outra série que teria sido preparada para o CPC de Goiânia, no início de 1964, cujo original não foi mais encontrado.

${ }^{10}$ As imagens das fichas, relativas às séries mencionadas, podem ser consultadas em Fóruns EJA Brasil. Disponível em: forumeja.org.br/fichasdecultura.paulofreire Acesso, 24/05/2021 
e a cultura. A figura humana está colocada no centro das relações estabelecidas. As relações entre seus elementos precisarão ser buscadas através da discussão e do diálogo que ocorrerão a partir das fichas. Em conformidade com a intenção metodológica de Paulo Freire, as fichas deveriam disponibilizar na "situação figurada (codificada)", a percepção das representações isoladas e a possibilidade de pensá-las em conjunto.

Para a criação das fichas, Brennand também se utiliza deste tema e da relação básica existente - a relação do homem com a realidade que o cerca. Na ficha número um criada por Brennand, a figura humana ocupa o centro do espaço, e se vincula ao contexto através de uma relação dinâmica; integrada e imersa no seu contexto. É o homem que, relacionando-se, é tensionado por todas os lados da realidade que habita. Seu próprio corpo é marcado por uma tensão entre seus lados, cada parte, um atributo; não só seus pés se ligam a terra e a cabeça pertence aos céus, como uma mão prediz o livro, enquanto a outra é força do trabalho. Se os pés fincam na terra, a cabeça olha distante, na direção do voo dos pássaros e do pensamento. E se os animais estão na terra e no céu, o homem é intermeio da cultura e da natureza

A imagem abre espaço para que os sentidos possam ser preenchidos pela vivência e imaginação de um observador, ainda que estes sentidos e significados possam nem mesmo ser intelectualizados, apenas sentidos ou pressentidos. Mas, se para Paz (2003, p. 47-48), a imagem não explica, mas convida-nos a recriá-la, por outro lado, ele nos diz também, que "a imagem explica-se a si mesma" e que "sentido e imagem é a mesma coisa [...] ela é seu sentido". Isto nos leva a pensar que a imagem não é apenas um signo abstrato - ou um receptáculo inerte - de um conteúdo que existe apenas fora dele mesmo, tal como as palavras, quando esvaziadas e desconectadas expressam apenas uma ideia abstrata, porque sem conexão com a realidade a que remetem.

A aparente contradição nas afirmações de Otávio Paz se esclarece porque, para ele, o modo que a imagem tem de explicar a si mesma, não é o da explicação, ou pelo menos, não é o da explicação da linguagem lógica e racional. A lógica da imagem é ela própria. Porém, não sendo direta, nem determinada, e podendo dizer mais de uma coisa ao mesmo tempo, ela só se explica quando requisita a experiência, a memória e a compreensão do observador; e é somente na coparticipação entre o que a imagem diz e o que o observador escuta (objetividade e subjetividade, como propõe Freire), que uma possível revelação se realiza. Como afirma Berino (2020, s/p) "as imagens pensam", e pensam e fazem pensar pelo modo que são e existem. 
Com relação às vivências com as imagens, acreditamos que nem sempre é necessário saber dizer intelectualmente a respeito das experiências estabelecidas. Contudo, no que diz respeito à prática pedagógica, esta observação é relativa a cada propósito e finalidade em questão; e, no caso do método de alfabetização de Paulo Freire, entendemos que há uma clara intenção de que aqueles educandos tivessem sim, uma compreensão daquilo que estavam sendo desafiados a solucionar, e, principalmente, que estavam sendo desafiados a pronunciar.

Conforme Fávero (2012, p. 11), no trabalho das fichas, Brennand buscou constituir também uma identidade estética com a arte popular e com a xilogravura, com a "simplicidade nos traços, a frontalidade, e escolha de motivos", recorrentes na produção popular artística. A cor utilizada nas fichas também remetia "à coloração do barro", conforme supracitado por Fávero (2012), visando aproximação com a materialidade tão vigente na produção cultural popular. Fatores estes que buscavam estabelecer um vínculo maior dos participantes com a imagem, evocando a materialidade e a realidade estética que lhes eram próximas.

Conforme as bases teóricas desenvolvidas por Paulo Freire, as fichas eram elaboradas após a investigação e escolha das palavras geradoras, e eram elaboradas como "codificações". Estas codificações poderiam acontecer num meio visual, auditivo, táctil ou audiovisual (FREIRE, 2019b, p. 168). As codificações são representações que expressam "aspectos da realidade [...] momentos do contexto concreto" (p. 167). Em todas as fichas podem ser percebidas "representações" que pretendem suscitar na vivência dos observadores a percepção ou descrição destes elementos representativos, apreendidos no contexto existente.

Freire (2019b, p. 169) nos diz também que "a codificação pode ser simples e complexa, conforme se use um só canal ou mais de um simultaneamente", de maneira que tem uma "estrutura de superfície" e uma "estrutura profunda". A estrutura de superfície é a situação codificada, ou seja, os elementos que podem ser objetivamente identificados e mesmo descritos, com a apreensão do conjunto que os constitui. Já "a 'estrutura profunda' não está visível; emerge na medida em que se verticaliza a leitura", ao que ele chama de "descodificação", e que se relaciona "com a razão de ser dos fatos que se acham expostos mas não desvelados na 'estrutura de superfície'”' (p. 169).

Conforme entendemos de suas palavras, no âmbito da descodificação, já não importa o valor em si que as representações têm, mas sim, o valor e significação que estabelecem na 
interação com o contexto como um todo, no momento em que, simultaneamente, cada coisa está constituindo seus próprios significados, e constituindo os dos outros elementos; ou seja, sentidos e significados não estão definidos a priori, mas se constituem no processo.

Em sua prática, de acordo com as finalidades que lhe são próprias, Freire menciona querer evitar dois tipos de riscos a respeito das fichas, que, no nosso entender, seria evitar dois tipos de produção de imagens que desviariam dos propósitos educativos estabelecidos. Um destes riscos seria o que "reduz a codificação a uma mensagem a ser transmitida" (FREIRE, 2019b, p. 171), um conteúdo explícito e direto, de maneira que não haja a participação do observador na construção dos significados. Como exemplo, cita a codificação propagandística, com seu efeito domesticador.

O segundo risco que menciona é quando a estrutura de superfície da codificação apresenta uma composição "de tal forma enigmática, fechada, que obstaculiza o trabalho descodificador" (FREIRE, 2019b, p. 171.). Aqui, gostaríamos de fazer uma consideração. Ainda que não especifique, neste segundo risco, poderiam estar incluídas as produções artísticas ou parte delas em que a "descodificação" se realize num âmbito não completamente intelectualizado, ou de aspecto enigmático, como menciona. O que, num primeiro momento, poderia criar certa contradição com as propostas de um pensamento estético-educativo. Porém, é preciso compreender que toda sua prática educativa, ainda que relacionada a um processo aberto que permita aos sujeitos uma elaboração e reelaboração do mundo, ao invés de submissão a uma ordem dada, tem como vinculação última o ato político, de natureza revolucionária, e que não pode deixar de considerar as condições existenciais concretas destes sujeitos educandos. Assim, toda proposta educativa criadora está "associada sobretudo a certas práticas claramente políticas de mobilização e de organização", para que possa "constituir-se num instrumento para o que Gramsci chamaria de ação contra hegemônica" (FREIRE, 2011, p. 31). O fundamento estético que propõe, assim como a perspectiva de criação, está na possibilidade de transformação da realidade. Criação e transformação da realidade precisam estar diretamente relacionadas, neste sentido, aproximando-se de grande parte da reflexão e utilização da arte na prática marxista.

Mas é possível dizer que estas experiências no âmbito das fichas e das descodificações também não são fixas, já que tal prática educativa é pautada no processo, e por isso, em constante reelaboração. Uma vez que as palavras geradoras e as codificações a elas referentes estão sendo estabelecidas em função da investigação dos homens em suas 
realidades, e considerando que estas "realidades" também não são fixas, mas estão em devir, então, na apreensão destes sujeitos, a própria "captação e a compreensão da realidade se refazem ganhando um nível que até então não tinham" (FREIRE, 2019a, p. 134) ${ }^{11}$. Se a prática se fundamenta na investigação concreta das condições existenciais, então, tanto as existências quanto as práticas não são consideradas fixas e estão também em processo, podendo requisitar novas soluções e novos tipos de imagens, em seu desenvolvimento.

Entendemos ser possível relacionar a codificação com a ideia de representação, tal como está indicado no pensamento do educador. A representação, como compreendemos, seria o signo que remete a uma ideia ou conceito pré-existente em nosso pensamento, tal como a palavra casa ou mesmo um desenho ou uma foto de uma casa, poderia remeter imediatamente a uma ideia pré-existente que temos do seu significado. A representação seria a junção instantânea do significante e do significado pré-existente.

O cineasta Serguei Eisenstein (2002), em seus estudos teóricos, nos oferece também reflexões interessantes para se pensar a relação entre as representações e as imagens. As representações podem se estabelecer por um ato instantâneo e, de certo modo, mecânico, por se tratar de relações pré-definidas na consciência, tendendo por isso, a se distanciar do real a que se refere, para ligar-se ao pensamento genérico e abstrato. As imagens, ao contrário, não se estabelecem previamente, constituindo-se na experiência e na memória de quem as apreendem. As imagens estão em devir. Com relação às abordagens sobre o processo de construção da imagem fílmica, Eisenstein nos diz:

A imagem [...] não é fixa ou já pronta, mas surge - nasce. A imagem concebida por autor, diretor e ator é concretizada por eles através dos elementos de representação independentes, e é reunida - de novo e finalmente - na percepção do espectador [...] a seu próprio modo, e a partir da urdidura e trama de suas associações, todas condicionadas pelas premissas de seu caráter, hábitos e condição social -, cria uma imagem de acordo com a orientação plástica sugerida pelo autor, levando-o a entender e sentir o tema do autor. É a mesma imagem concebida e criada pelo autor, mas esta imagem, ao mesmo tempo, também é criada pelo próprio espectador (EISENSTEIN, 2002, p. 28-29 [grifo do autor])

\footnotetext{
${ }^{11}$ A artista e educadora Fayga Ostrower (2008, p. 165), nos oferece uma abordagem semelhante: "A cada síntese, a cada novo nível de compreensão que é possível alcançar, corresponde a base para o aparecimento de novas possibilidades de ser e de criar. A cada síntese se requalificam os limites que funcionam como referencial para o desenvolvimento subsequente. O próprio referencial é continuamente requalificado pelo mesmo processo que ele referencia e qualifica".
} 
Para Eisenstein (2002, p. 20), o processo dinâmico de surgimento de uma imagem se dá através de uma "cadeia de representações" - "uma cadeia de representações intermediárias que, juntas; formam a imagem"; cadeia esta que institui uma relação entre os sentidos propostos na produção e os que são encontrados na recepção. Este sistema de uma cadeia de representações nos parece possível de ser aproximada do que Paulo Freire considera a respeito da codificação; e, em nosso modo de correlacionar, a descodificação, por sua vez, corresponderia ao surgimento da imagem, espaço onde se unificam objetividade e subjetividade, as palavras e as realidades, as formas e as vivências, em suma, espaço de superação da dicotomia.

A questão que precisamos considerar é o que acontece no que Freire chama de "estrutura profunda", como aquilo que não está visível. É justamente neste espaço que não está dito, que a leitura e articulação dos significados acontecem. No entanto, nas fichas, as lacunas entre as representações retiradas do real, que são suscitadas na memória e compõem a dinâmica da leitura proposta, não apresentam necessariamente uma oposição entre seus termos, como ocorre nos filmes de Eisenstein. Elas estão, de certo modo, vinculadas à própria vivência dos educandos, possibilitando a estes um pensar sobre a própria realidade em que estão integrados, objetivando, neste momento, um pensar interligado a sua experiência do mundo.

No processo educativo com as fichas, Freire (2019a) partia do foco nas representações que as imagens poderiam despertar, para, a partir daí, através do diálogo, ocorrer as interações entre os elementos em questão: com as experiências de cada um podendo construir as relações e implicações de uma coisa com a outra, cada um se posicionando perante as coisas e o todo, podendo superar o caráter dicotômico das representações abstratas.

De certo, existe um caráter pedagógico e didático nas fichas. Para realizá-las, Brennand teria absorvido uma dada visão de mundo que estaria em correspondência com a condição existencial dos educandos em questão e com os propósitos da prática pedagógica de Paulo Freire, porém, distintos, talvez, de sua própria visão de mundo. Há, por exemplo, em parte das fichas produzidas por Brennand, um antropocentrismo, com o homem inserido no centro das relações - que está relacionado à pedagogia em questão -, mas que, talvez, não corresponda tanto a sua produção artística mais autoral, principalmente na cerâmica, que é 
fundamentalmente marcada por um zoomorfismo e animismo de um universo míticoreligioso. Isto nos leva a pensar que a produção das fichas leva em consideração um caráter pedagógico, que tem como questão uma determinada visão de mundo, tendo um propósito que se vincula a situação existencial dos educandos em questão; a busca da afirmação deste homem e de sua ação no mundo.

O que consideramos interessante é que na arte, e pela arte, as imagens não têm um compromisso com a verdade absoluta, e sim, com as verdades relativas ou parciais; aquelas que se constituem como uma verdade provisória, que é válida num dado contexto, num dado momento, numa dada 'realidade', sem negar a existência de outras ${ }^{12}$. São verdades que habitam mundos paralelos, ainda que possam ser afins ou divergentes. São como parábolas ou como poesias; em que as suas verdades não negam outras, porque cada uma constitui-se e tem validade dentro da sua própria lógica, em que instituem sua própria realidade e razão de ser.

Podemos perceber este dinamismo nas próprias imagens produzidas por Brennand para as fichas. Se em algumas fichas, há certo antropomorfismo, com o homem ocupando um lugar central no espaço, outras, aproximam-se de algumas gravuras de cordel com seus elementos mágicos e alegóricos, que povoam o imaginário popular. Segundo Fávero (2012, p. 12), a ficha número dois tem como título "A natureza - mediadora da comunicação entre o homem e o mundo da cultura", e, na imagem construída por Brennand, as figuras humanas, mulher e homem, têm seu lugar num mosaico, junto a peixes, rio, plantas, animais domésticos e selvagens que aparecem em cima e em baixo, de um lado e do outro, numa trama gráfica. Sugere uma narratividade diferenciada da primeira ficha. A figura humana não nos parece estar no centro de todas as relações, mas é parte integrante de uma trama que a engloba. Há uma natureza, ao mesmo tempo, material e imaterial, terrena e imaginária, que a dimensiona na existência.

As narratividades de cada imagem não negam umas às outras. Cada imagem constitui seu próprio princípio, sua validade ou sua verdade relativa. Acreditamos que a arte não tem como fundamento a verdade, mas as possibilidades. Refletimos a partir disto que diante de uma imagem há sempre um pensamento em suspenso: o que a imagem nos conta? Quais

\footnotetext{
12 O também cineasta russo Andrei Tarkovski (1998, p. 42) expressa esse sentimento dizendo que a arte se assemelha a "um infinito sistemas de esferas", cada esfera correspondendo a "uma imagem nova e insubstituível do mundo, um hieroglifo de absoluta verdade [...]".
} 
construções narrativas podem fazer sugerir, revelar? Como ela expressa as concepções de quem a construiu, pelo menos relativa àquela construção específica (considerando que um autor pode expressar distintas concepções na construção de suas imagens)? E finalmente, como eu penso e construo minhas próprias narrativas a partir dos elementos, vivências e associações que ela faz despertar e ressoar em mim?

Com relação à pedagogia com as fichas de cultura, acreditamos que, para Paulo Freire, o que importava era como aqueles educandos iriam entrar em contato com as representações dispostas nas imagens, e como a partir disto iriam construir também suas próprias narrativas, seus pontos de vistas, seus pronunciamentos, em diálogo com as imagens e com os demais participantes desta dinâmica nos Círculos de Cultura.

Como menciona Berino (2017, p. 184) a respeito de uma "educação como prática da liberdade" em Paulo Freire, "o conhecimento é artístico no sentido de criação". O pensamento é estético na sua dimensão criadora, necessária a nossa compreensão e percepção do mundo em constante processo: “uma dimensão estética que a nós, latino-americanos, não convém sacrificar em favor de uma ciência puramente realista, porque o 'quefazer' freireano não sossega o nosso desejo por uma outra vida que vá além do imaginário permitido pelo poder" (BERINO, 2018, p. 337).

\section{CONSIDERAÇÕES FINAIS}

O método de alfabetização se demonstrou enquanto uma educação pensada para as classes populares subalternizadas, que não cumprem apreender friamente os conteúdos a eles impostos através de uma educação falaciosa que se pretenda neutra. A estes "oprimidos" cabe não outra que uma educação em estado de poesia. Como sujeitos em estado de troca, em diálogo. Mas também, como sujeitos políticos em processo, dotados de resistência para se fazer realizar seus modos de ver, ser, fazer, no mundo.

É possível perceber na prática educativa freireana, a preocupação política quanto ao recebimento da linguagem não como algo acabado e unívoco. Suas estratégias buscam colocar os sujeitos para debruçarem-se sobre os sentidos das coisas, para reencontrá-los dentro de si, para recriarem, para ocupar seus espaços como sujeitos também criadores de linguagem. Para estimular um espanto e um questionamento sobre a linguagem instituída, para conscientizar a respeito de narrativas que não são neutras ou naturais - como se pretende parecer -, mas 
que têm pertencimento, objetivos, finalidades. Enfim, para estimular uma atividade de criação e recriação sobre a linguagem, que deve, por uma função educativa e política, ser entendida sempre em estado nascente, poético, em devir.

É neste sentido que, na obra A África ensinando a gente, quando menciona que: "Um povo sela a sua libertação na medida em que ele reconquista a sua palavra" (FREIRE, 2003, p. 29), o sentido implícito no termo "palavra", ultrapassa em muito uma questão meramente instrumental; relaciona-se a uma reencarnação das palavras, de todo um sentido fabulatório sobre as mesmas, de modos de ser, de expressar, de fazer e construir. Reintegra às palavras sua dimensão estética, poética; a dimensão dos modos de vivência e existência no mundo.

\section{REFERÊNCIAS}

AMIEL, Vincent. A Estética da Montagem. Tradução de Carla Bogalheiro Gamboa. Lisboa: Texto\&Grafia, 2010.

BENJAMIN, Walter. Que é o teatro épico? Um estudo sobre Brecht. In: BENJAMIN, Walter. Magia e Técnica, Arte e Política. Tradução de Sérgio Paulo Rouanet. São Paulo: Brasiliense, 1994a. p. 78-90.

BENJAMIN, Walter. O autor como produtor. In: BENJAMIN, Walter. Magia e Técnica, Arte e Política. Tradução de Sérgio Paulo Rouanet. São Paulo: Brasiliense, 1994b. p. 120-136.

BERINO, Aristóteles. Paulo Freire Esteta: Arte, Fotografia e Cinema. E-Mosaicos, Revista Multidisciplinar de Aplicação Fernando Rodrigues da Silveira (CAP-UERJ), [s.I.], v. 6, n. 13, p. 182-192, dez. 2017a.

BERINO, Aristóteles. Paulo Freire: A trama das imagens entre o currículo e a pedagogia da imagem. Pedagogia da imagem, Rio de Janeiro, 17 de out. 2017b. Disponível em:

http://aristotelesberino.blogspot.com/2017/10/paulo-freire-trama-das-imagens-entreo.html. Acesso em: 20 out. 2020.

BERINO, Aristóteles. Para Ser um Ser no Mundo: A Humanização é uma Poética em Paulo Freire. Revista Teias, Rio de Janeiro, v. 19, n. 55, p. 329-339, out./dez. 2018.

BERINO, Aristóteles. Paulo Freire: Por uma educação crítica, democrática e transformadora. Pedagogia da imagem, Rio de Janeiro, 25 de out. 2019. Disponível em:

http://aristotelesberino.blogspot.com/2019/10/texto-que-preparei-para-minha.html. Acesso em: 20 nov. 2020.

BERINO, Aristóteles. Para ser um ser no mundo. Pedagogia da imagem, Rio de Janeiro, 26 de abr. 2020. Disponível em: http://aristotelesberino.blogspot.com/2020/04/para-ser-um-serno-mundo.html. Disponível em: 15 set. 2020.

Ideação. Revista do Centro de Educação, Letras e Saúde. v. 23, n², 2021. e-ISSN: 1982-3010. 
BUENO, André. O Arcaico e o Moderno no Brasil: Variações em torno de uma Educação interrompida. Trabalho, Educação e Saúde, [s.l.], v. 6, n. 2, p. 259-281, jul./out. 2008.

Disponível em: https://www.redalyc.org/pdf/4067/406757015003.pdf. Acesso em: 15 set. 2020.

CHAUÍ, Marilena. Seminários. O Nacional e o Popular na Cultura Brasileira. São Paulo: Brasiliense, 1983.

EISENSTEIN, Sergei. O Sentido do Filme. Tradução de Teresa Ottoni. Rio de Janeiro: Jorge Zahar, 2002.

FÁVERO, Osmar. As Fichas de Cultura do Sistema de Alfabetização de Paulo Freire: um "Ovo de Colombo". Revista Linhas Críticas, [s.I.], v. 18, n. 37, p. 1-20, set./dez. 2012.

FREIRE, Paulo. Educação como Prática da Liberdade. São Paulo: Paz e Terra, 1994.

FREIRE, Paulo. A África ensinando a gente. São Paulo: Paz e Terra, 2003.

FREIRE, Paulo. A importância do ato de ler: em três artigos que se completam. São Paulo: Cortez, 2011.

FREIRE, Paulo. Pedagogia do Oprimido. São Paulo: Paz \& Terra, 2019a.

FREIRE, Paulo. Cartas à Guiné-Bissau. Registros de uma Experiência em Processo. São Paulo: Paz \& Terra, 2019b.

OSTROWER, Fayga. Criatividade e Processos de Criação. Petrópolis: Vozes, 2008.

PAZ, Otávio. A Imagem. In: PAZ, Otávio. Signos em Rotação. Tradução de Sebastião Uchoa Leite. São Paulo: Perspectiva, 2003. p. 37-50.

SCHWARZ, Roberto. Cultura e Política, 1964-1969. In: SCHWARZ, Roberto. O pai de família e outros ensaios. São Paulo: Companhia das Letras, 2008. p. 70-111.

TARKOVSKI, Andrei. Esculpir o Tempo. Tradução de Jefferson Luiz Camargo. São Paulo: Martins Fontes, 1998.

Recebido em 24 de agosto de 2020.

Aprovado em 01 de novembro de 2020.

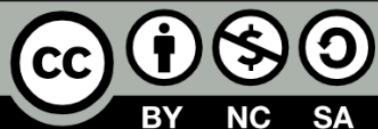

